\section{Smoking cessation advice: knowledge, attitude and practice among clinical dental students}

\author{
S. Clareboets, ${ }^{1}$ V. Sivarajasingam ${ }^{2}$ and I. G. Chestnutt ${ }^{3}$
}

IN BRIEF

- Smoking related issues are currently high on the public health agenda.

- This study provides evidence that clinical dental undergraduates are willing to give smoking cessation advice to their patients but perceive barriers in giving such advice.

- This study further informs the development of future dental undergraduate education in the UK.

Objective To examine knowledge, attitude and current practice among clinical dental students in giving smoking ces-
sation advice (SCA) and to explore the barriers to this activity. Design and setting A self-administered questionnaire
survey of clinical dental students at Cardiff University School of Dentistry. Materials and methods In 2008, clinical dental
students were surveyed ( $n=181)$. Information on smoking cessation practices, students' attitude, potential barriers and
level of preparedness to deliver SCA, knowledge of association between tobacco use and various pathological conditions
and demographics and tobacco use by clinical dental students were gathered. Results One hundred and sixty-one (89\%)
students responded. All students enquired about patient smoking habits in the previous three months but were inconsist-
ent in providing SCA - only one third of students gave SCA all or nearly all the time. Students had good knowledge of the
associated health risks with tobacco use. A majority of students perceived barriers in providing patients with SCA. Those
who provided advice were more likely to have positive attitudes and reported feeling adequately prepared. Conclusions
Dental educators should address students' perceived barriers towards providing SCA when designing smoking cessation
curricula in order to produce dentists who are confident and competent to provide this important health care intervention.

\section{INTRODUCTION}

Smoking is the single most important public health challenge facing the NHS. ${ }^{1}$ Smoking-related diseases are responsible for an estimated 18\% of deaths in England and Wales ${ }^{2}$ and cost the NHS approximately £1.7 billion per year. ${ }^{3}$ Smoking impacts on oral health by increasing the prevalence and severity of periodontal disease, impairing wound healing and increasing the risk of cancer in a dosedependent relationship. ${ }^{4}$ The detrimental effects on general health of tobacco smoking are well documented and on average, cigarette smokers die ten years younger than non-smokers. ${ }^{5}$

Surveys of dentists have consistently shown willingness to participate in tobacco cessation campaigns and to undertake smoking cessation advice (SCA) training,

${ }^{1}$ Dental Student, ${ }^{2 *}$ Senior Clinical Lecturer in Oral Surgery, ${ }^{3}$ Professor of Dental Public Health, Cardiff University School of Dentistry, Heath Park, Cardiff, CF14 4XY

${ }^{*}$ Correspondence to: Dr Vaseekaran Sivarajasingam Email:sivarajasingam@cardiff.ac.uk

\section{Refereed Paper}

Accepted 24 November 2009

DOI: $10.1038 /$ sj.bdj.2010.158

${ }^{\circledR}$ British Dental Journal 2010; 208: 173-177 however, widespread acceptance of tobacco use interventions in the dental setting have lagged behind and limitations in primary care resources have curtailed further efforts. ${ }^{6}$ The agenda for UK stop smoking policy for the last decade has been directed by the White Paper on tobacco, 'Smoking kills.' Following on from this, various Department of Health policy documents have emphasised the importance placed on members of the dental team to routinely inquire about their patients' tobacco use and give advice and support. ${ }^{3,-11}$ Dental professionals can play an important role in preventing adverse health effects by promoting smoking cessation, as more than $50 \%$ of smokers see a dentist in any one year. ${ }^{12-14}$

As future dentists, dental student knowledge, attitude and practice related to the provision of SCA to patients have not been assessed. The aim of this study was to assess this in a UK dental school and to explore barriers to giving such advice to patients.

\section{MATERIALS AND METHODS}

\section{Study design}

A self-administered questionnaire survey of clinical dental students (years 3, 4 and 5) was undertaken at Cardiff University School of Dentistry in February 2008 ( $n=181)$ for which ethical approval was obtained. The use of questionnaires allowed for groups of students to be surveyed at a time, a shorter data collection period and was considered more suitable for recording potentially sensitive or personal information relating to current smoking habits of students than personal interviews. In constructing the questionnaire, the survey developed by the US National Dental Tobacco Free Steering Committee to assess adherence to the four As model of cessation advice (Ask, Advise, Assist and Arrange for follow up), ${ }^{15}$ which has been advocated for use by UK dentists, ${ }^{16,17}$ was used as a model. A pilot study was undertaken with a group of nine clinical dental students (three from each clinical year). In the pilot, respondents were asked for feedback on clarity of instructions and questions, whether there was any difficulty in answering the questions or any ambiguity as to what sort of answer was required. Time taken to complete the questionnaire was recorded and feedback sought on the length of the questionnaire. The study questionnaire comprised 16 questions relating to the provision of 
SCA by clinical dental students including their self-reported practice, potential barriers and student attitudes for giving advice, type of advice given, student preparedness and knowledge of associations between tobacco use and ill health. In one of the questions a six item tool to generate a summary score to describe students' attitudes was used to produce an average response for each student. This was carried out by assigning every positive answer a score of 1 , neutral a score of 2 and negative a score of 3 and producing a mean score, ranging from 1 representing a belief that giving smoking cessation is appropriate, important, effective, a duty of every dentist, and an activity students should be trained to provide, to 3 representing the opposing views. These data were coded to give three groups to allow for analysis. Cut off points were arbitrarily set at 1 (students with positive attitudes) and at 1.5 (students with mostly positive views but up to two neutral or one negative statements) and a third group with less positive views. A closed-style of questioning was mainly used, with only one question inviting an open answer. The majority of questions utilised tick-box responses, with Likerttype questions.

\section{Sample}

Years 3 and 4 dental students received questionnaires after compulsory didactic lectures. Final year students were approached during an optional talk. Due to low attendance it was not possible to reach all final year students simultaneously and follow up was achieved by delivering questionnaires to students at the end of clinical sessions. The questionnaire was introduced with a detachable information sheet informing students that all answers were anonymous and no questions were compulsory. One author (SC) was present to introduce and administer the questionnaire and completed questionnaires were placed into a collection box kept outside lecture theatres and clinics. There was also an enclosed response box located at the school's academic office if students wished to complete the questionnaire in their own time.

\section{Statistical analyses}

Descriptive statistics were generated for relevant results. Univariate analyses were

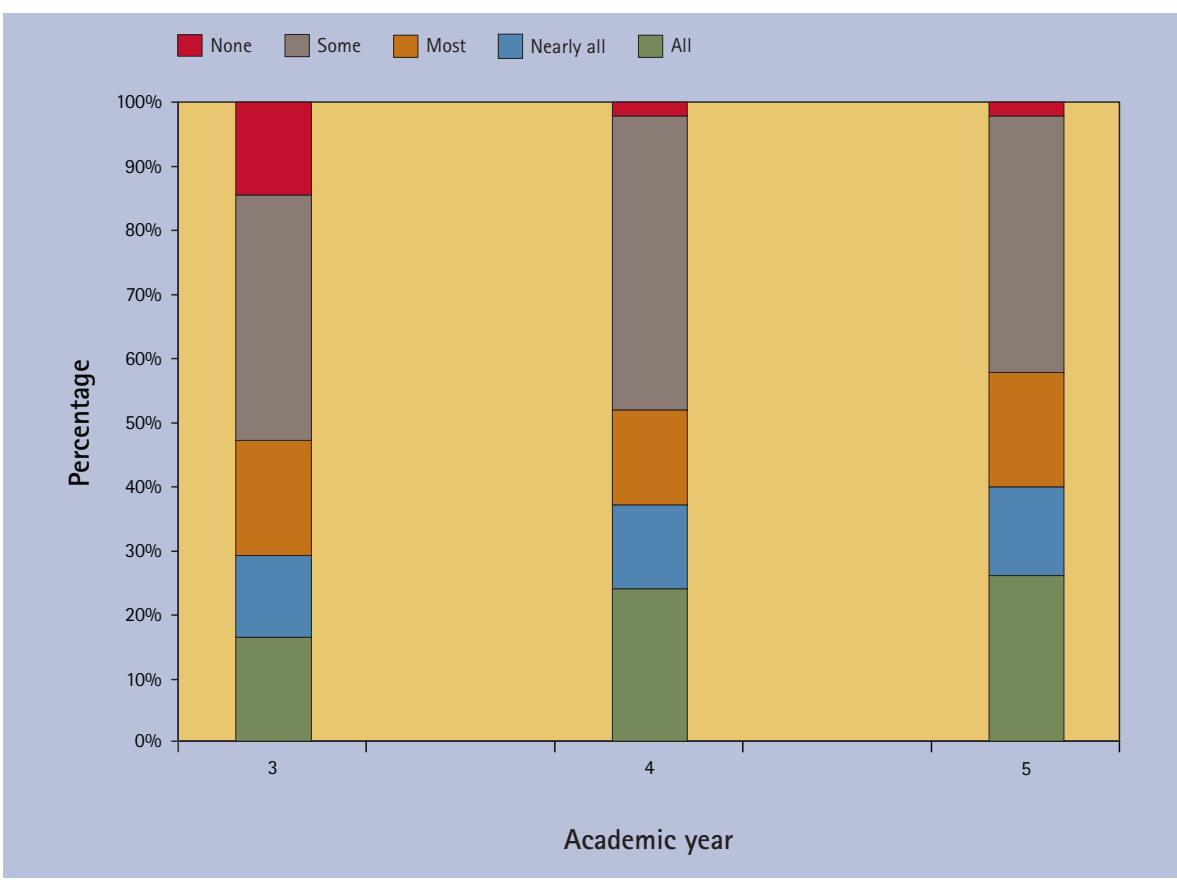

Fig. 1 The frequency with which clinical dental students claimed to provide smoking cessation advice

Table 1 Proportion (\%) of clinical dental students who gave smoking cessation advice to patients by year of study

\begin{tabular}{|l|l|l|l|l|}
\multirow{2}{*}{ Smoking Cessation Advice } & \multicolumn{2}{l}{ Academic Year } & \multicolumn{2}{l}{ Total } \\
\cline { 2 - 5 } & 3 & 4 & 5 & \\
\hline Negative effects of smoking on dental health & 78.2 & 90.7 & 94.0 & 87.4 \\
\hline Information on the benefits of stopping smoking & 58.2 & 59.3 & 64.0 & 60.4 \\
\hline Negative effects of smoking on general health & 40.0 & 66.7 & 66.0 & 57.2 \\
\hline Practical advice on stopping ie use of NRT & 3.6 & 18.5 & 14.0 & 11.9 \\
\hline Information on any smoking cessation service & 9.1 & 16.7 & 6.0 & 10.7 \\
\hline Strategies for stopping ie setting quit date & 7.3 & 13.0 & 12.0 & 10.7 \\
\hline Effects of passive smoking & 1.8 & 5.6 & 4.0 & 3.8 \\
\hline Any written information & 0 & 5.6 & 2.0 & 2.5 \\
\hline
\end{tabular}

Table 2 Perceived barriers to providing smoking cessation advice by clinical dental students

\begin{tabular}{|l|l|l|l|l|l|l|l|}
\hline & \multicolumn{2}{|l|}{ Strong barrier } & \multicolumn{2}{l|}{ Some barrier } & \multicolumn{2}{l}{ No barrier } \\
\hline & $n$ & $\%$ & $n$ & $\%$ & $n$ & $\%$ \\
\hline Patient disinterest in receiving advice & 132 & 83.0 & 26 & 16.4 & 1 & 0.6 \\
\hline Lack of training to give effective advice & 75 & 47.2 & 68 & 42.8 & 16 & 10.1 \\
\hline Lack of patient education materials & 66 & 41.8 & 77 & 48.7 & 15 & 9.5 \\
\hline Lack of available time during appointments & 51 & 32.1 & 88 & 55.3 & 20 & 12.6 \\
\hline Concerns about effectiveness & 40 & 25.2 & 87 & 54.7 & 32 & 20.1 \\
\hline Amount of time required to give advice & 39 & 24.5 & 101 & 63.5 & 19 & 11.9 \\
\hline Insufficient support from supervising staff & 33 & 20.8 & 81 & 50.9 & 45 & 28.3 \\
\hline Possibility of damaging patient rapport & 20 & 12.7 & 104 & 65.8 & 34 & 21.5 \\
\hline N = number of responses & & & & & & \\
\hline
\end{tabular}


performed with the non-parametric Chisquare test to determine the effects of demographics, level of preparedness and students' attitude in giving SCA to patients. The association between perceived barriers and demographic variables was also examined by cross-tabulation and statistical significance measured with chi-square tests. Statistical significance was set at $\mathrm{P}<0.05$. To allow sufficient numbers for the statistical test to produce meaningful outcomes, results for questions relating to the frequency with which students advised cessation and the time spent on this were grouped into three outcomes. Students' recent practice was grouped as all or nearly all (90-100\%), most (50-89\%) and less than half (0-49\%) and time spent as less than one minute, one to two minutes and more than two minutes. Data were analysed using SPSS version 11.5 for Windows.

\section{RESULTS}

The overall response rate was $89 \%$ (161/181), 90\% of year 3 (55/61), 84\% of year $4(54 / 64)$ and $89 \%$ of year $5(50 / 56)$. Respondents were 56\% female and 44\% male. The majority (96\%) of students reported currently being non-smokers and $68 \%$ had never smoked.

\section{Smoking cessation advice}

All students reported having enquired about patients' smoking habits they had treated in the previous three months and the majority (86\%) did so all or nearly all of the time; fewer than one in ten students enquired less than half the time. Almost all (94\%) students surveyed recorded patients' smoking habits in dental notes. Approximately one third of clinical dental students advised patients who currently smoked to stop smoking all or nearly all of the time, and just over half of all students advised patients to stop smoking more than $50 \%$ of the time. A small minority of students advised none of their patients who smoked to stop smoking - most of these students were in their first clinical year (Fig. 1).

Advice given by students most frequently consisted of the negative effects of smoking on dental and general health. In just over one in eight instances practical advice on stopping smoking ie the use of nicotine replacement therapy was given. When asked to specify any other advice given to patients, very few students opted to provide an answer (Table 1). These did, however, include calling the NHS stop smoking helpline, the cost implications of smoking, to visit their general medical practitioner, specialist smoking cessation services and to stop after an extraction.

When giving advice few students (12.1\%) spent more than three minutes and most gave advice for 1-2 minutes. Students, however, felt that they should be spending more time than they do. None of the respondents felt no time should be allocated to giving SCA.

\section{Barriers to giving advice}

Patient disinterest in receiving advice was perceived as a strong barrier by over $80 \%$ of students and a lack of training to give effective advice was identified as a strong barrier by almost half. Other perceived barriers included lack of patient education materials in the clinic (about 50\%), lack of available time during appointments, concerns about effectiveness of giving patients advice, the possibility of damaging patient rapport (13\%) and insufficient support from staff (Table 2). Students perceived barriers to providing SCA to be gender dependent. Females were more likely to report the possibility of damaging patient rapport and insufficient support from supervising staff as barriers than their male colleagues. Alternatively, males were more likely to report concerns about effectiveness and a lack of training to give advice as 'no barrier' to give advice.

The majority of Cardiff dental students held positive views regarding the role of the dentists in providing SCA; 85\% of students considered it an important activity, 84\% thought it was an activity dental students should be trained to provide and $86 \%$ felt it was an effective health care intervention. Over $72 \%$ thought it was appropriate for a dental professional to give SCA during a dental appointment. Scores for attitude ( 1 = entirely positive, 2 $=$ neutral and 3 = entirely negative) were grouped to allow for statistical analysis. Students with greater clinical experience had higher positive attitude in providing SCA ( $p=0.03)$. Students who had positive attitudes were significantly more likely to advise patients to quit ( $\mathrm{p}=0.003$ ).

Students were divided when questioned as to how prepared they felt to provide patients with advice on quitting smoking. Almost half of all students felt not well or not at all prepared. Of those respondents who felt adequately or better prepared only $7.5 \%$ felt very well and $18.8 \%$ felt well prepared. There was no statistically significant difference between how prepared students felt and year of study $(\mathrm{p}=0.23)$ or their gender $(p=0.29)$. However, levels of preparedness were significantly associated with the time spent on giving advice $(p=0.004)$, frequency with which students gave advice $(p=0.002)$ and whether students reported having received formal training in giving SCA ( $p=0.001)$.

\section{Knowledge}

Over 97\% of students indicated that there was a strong or moderate association between tobacco use and lung and oral cancer, periodontal disease, impairment of wound healing, implant failure and carcinoma of the larynx. Nine out of ten students knew there was a relationship with tobacco use and candidiasis and that there was an association with leukoplakia. Students were most likely to report not knowing whether an association existed between odontogenic tumours and tobacco use; only $26 \%$ correctly identified that there was no association but six out of ten students thought that there was an association.

\section{DISCUSSION}

This survey of clinical dental students at a UK dental hospital has shown that students have good knowledge of the effects of tobacco on dental and general health and a positive attitude towards providing SCA to patients. However, students perceived barriers to providing advice. Over $90 \%$ of students routinely recorded smoking habits of their patients which is coherent with smoking cessation guidelines for all health professionals. ${ }^{3,17-19}$ This practice has not always been reported by UK dentists - only $6 \%$ of Scottish dentists always recorded smoking history and 35\% never $\operatorname{did} .^{20}$ There was more variation among students in advising patients to stop smoking. Recommendations for health care professionals are that all smokers be advised to quit, ${ }^{17}$ and the study reported here does not reflect this. Students are not alone in this position - an omnibus survey by the British Dental Association in 2002 showed 
that $64 \%$ of UK dentists stated that they gave patients advice on tobacco cessation 'fairly regularly' or 'always', whereas $52 \%$ of students advised most ( $>50 \%$ ) of their patients.

Despite the publication of guidelines on the implementation of effective stop smoking interventions in the dental setting and the positive views held by many UK dentists towards smoking cessation strategies, ${ }^{21}$ many UK dentists still report barriers to providing SCA.22 These include concerns about patient resistance, ${ }^{23}$ lack of time ${ }^{24}$ and lack of methods for financial reimbursement. ${ }^{25}$ While issues regarding financial remuneration are not applicable to students many of the barriers are the same. In this study, patient disinterest in receiving advice was the most frequently reported barrier, despite evidence to the contrary showing that patients believe dentists ${ }^{26}$ and dental students ${ }^{27}$ have an important role in encouraging smoking cessation. Overall, student attitude in providing SCA was positive - over $84 \%$ agreed that giving SCA is important and an effective activity and in which they should receive training. The current practice of most students, who gave advice, is to spend less than three minutes with over $12 \%$ of students estimating they gave advice for three minutes or more. While brief advice given over three minutes is effective, ${ }^{17}$ there is a gap in the evidence base for the effectiveness of brief interventions of less than two minutes. Meta-analyses have found that increasing the number of advice sessions is associated with increase in abstinence rates. ${ }^{12}$ Brief advice has also been shown to be an extremely cost effective health care intervention. ${ }^{28}$

More recently, in the UK, local specialist smoking cessation services have been developed so that health care workers can refer patients who have been identified as smokers and who are willing to quit. Such a referral is acknowledged as highly cost-effective and an important part of the national strategy. The existence of these specialist smoking cessation services has met with widespread approval from general medical practitioners (GMPs). ${ }^{29}$ A survey of Scandinavian GMPs showed that the shortage of smoking cessation experts to whom patients could be referred was the most common barrier to GMPs discussing cessation with their smoking patients. ${ }^{30}$ In this study clinical dental students failed to acknowledge the presence of specialist smoking cessation services in the UK. Dental students should be aware of how and where to refer patients who smoke and who are willing to quit smoking.

The dental team has an important role to play in encouraging patients to quit using tobacco as they are ideally placed to recognise and point out the damage caused by tobacco to oral tissues and highlight the general health benefits of quitting and to refer on to professional cessation services if appropraite. ${ }^{6}$ In this study the negative effects of smoking on dental health were most likely to be included in any advice given to patients. Students had a good level of knowledge about potential health implications for tobacco users - the majority of students correctly identified tobacco use with a variety of dental and other pathologies. However, over 11\% did not know the potentially important association between leukoplakia and tobacco use. There was clearly a poor level of knowledge regarding the level of association between tobacco use and odontogenic tumours, this produced the highest number of 'don't know' responses and was also the most likely to be answered incorrectly. Considering that at the time of the survey year 3 had not completed the oral medicine module of the course, the results overall are encouraging.

Although the majority of students stated that their education should include SCA, only half of all respondents felt adequately or better prepared in providing advice to their patients. This is similar to previous surveys which found only $40-60 \%$ of students felt adequately trained. ${ }^{15,31}$ Cardiff, like the majority of UK dental schools, has no formal course aimed purely towards SCA. ${ }^{32}$ However tobacco issues are integrated into several parts of the curriculum including - as part of the periodontology course smoking is identified as a risk factor and there is emphasis placed on the effect of cessation on treatment outcome throughout years 3 and 4 . The effect of tobacco on oral health is introduced to the curriculum as part of oral medicine and pathology teaching and in chairside teaching during years 3 and 4. In addition, tobacco use and health promotion is introduced as part of the public health component of the course which takes place in year $4 .^{33}$ This study was carried out before this teaching was delivered to year 4 students. A survey of American dental schools found that dental educators felt they had a duty to provide education on SCA and that time constraints on the curricula were the main obstacle in providing training to undergraduates. ${ }^{34}$ In the UK the minority of dental schools that took part in a Health Development Agency survey of dental undergraduate and postgraduate education and training in tobacco issues had a specific module devoted to tobacco and oral health. ${ }^{32}$ The most common areas of the curricula in which training was included were periodontology, oral pathology, dental public health and human health and disease. Half of the responding schools included smoking cessation as part of undergraduate or postgraduate training. ${ }^{32}$

The education of oral health care professionals in offering SCA in their clinical environment is a priority ${ }^{35}$ and smoking counselling should be viewed as a fundamental part of the dental curriculum. ${ }^{4}$ This is reflected in a document prepared by the Association for Dental Education in Europe which details that students should 'have knowledge concerning the effects of tobacco on the oral mucosa and ways in which to help patients who wish to stop using tobacco'. ${ }^{36}$ Similarly the Quality Assurance Agency for Higher Education states that dental graduates should recognise their role in and responsibility for improving the general and oral health of the community through treatment strategy, education and service. ${ }^{37}$ Direction for UK dental school curricula is fundamentally governed by guidance published by the General Dental Council. ${ }^{38}$ Revision of the curricula would provide an opportunity for greater emphasis to be placed on tobacco cessation as a core learning outcome. ${ }^{3}$ Ultimately the implementation of these directives is determined at a local level and barriers to providing SCA on clinics may be overcome by identifying models successfully employed at schools around the world. ${ }^{34}$ Until adequate emphasis is placed on integrating the principles and practice of providing SCA into the undergraduate experience including the existence of national specialist smoking cessation services we can expect there to be a continued 'dearth of practitioners willing to undertake such work with enthusiasm.39 


\section{CONCLUSION}

Despite having knowledge of associated health risks with tobacco use and positive attitudes towards giving SCA to patients, clinical dental students perceived barriers to providing SCA. The challenge therefore for the undergraduate curricula is to address the motivation, reservations and concerns that govern students' behaviour, to ensure that when students graduate they do so not only with the knowledge but the confidence they need to provide what is known to be an effective and important health care intervention and to be able to refer patients interested in stopping smoking to an appropriate source of help.

1. Watt R G, Daly B, Kay E J. SCA within the general dental practice. Br Dent J 2003; 194: 665-668.

2. Statistics on Smoking, England. The Information Centre 2006. http://www.ic.nhs.uk/statistics-anddata-collections/health-and-lifestyles/smoking/ statistics-on-smoking-england-2006 [accessed 25 January 2008].

3. Department of Health. Smokefree and smiling helping dental patients to quit tobacco. Publication no. DH 074970. London: The Stationery Office, 2007.

4. Johnson N W, Bain C A. Tobacco and oral diseases. BrDent J 2000: 189: 200-206.

5. Doll R, Peto R, Boreham J, Sutherland I. Mortality in relation to smoking: 50 years' observations on male British doctors. BMJ 2004; 26: 1519-1533.

6. Warnakulasuriya S. Effectiveness of tobacco counselling in the dental office. J Dent Educ 2002; 66: 1079-1087.

7. Department of Health. Smoking kills: a white paper on tobacco (1998a). London: The Stationery Office, 1998.

8. Department of Health. Report of the Scientific Committee on Tobacco and Health (1998b). London: The Stationery Office, 2000.
9. Modernising NHS dentistry - implementing the NHS plan. London: Department of Health, 2000.

10. NHS dentistry: options for change. London: Department of Health, 2002.

11. Choosing better oral health: an oral health plan for England. Department of Health: Dental and Ophthalmic Services Division, 2005.

12. Walsh M M, Ellison J A. Treatment of tobacco use and dependence: the role of the dental professional. J Dent Educ 2005; 69: 521-537.

13. Martin L M, Bouquot J E, Wingo P A, Heath C W $\mathrm{Jr}$. Cancer prevention in the dental practice: oral cancer screening and tobacco cessation advice. J Public Health Dent 1996; 56: 336-340.

14. Chestnutt I G. What should we do about patients who smoke? Dent Update 1999; 26: 227-231.

15. Yip J K, Hay J L, Ostroff J S, Stewart R K, Cruz G D. Dental students' attitudes toward smoking cessation guidelines. J Dent Educ 2000; 64: 641-650.

16. Department of Health. Smoking cessation guidance for primary care dental teams. London: The Stationery Office, 25 May 2007.

17. The Public Health Interventions Advisory Committee NICE public health intervention guidance. Brief interventions and referral for smoking cessation in primary care and other settings. Publication no. PHI001. London: Department of Health, 2006

18. Department of Health and the British Association for the Study of Community Dentistry. Delivering better oral health: an evidence-based toolkit for prevention. Publication no. DH 078742. 2007.

19. Rikard-Bell G, Groenlund C, Ward J. Australian dental students' views about smoking cessation counseling and their skills as counselors. J Public Health Dent 2003; 63: 200-206.

20. Chestnutt I G, Binnie V I. Smoking cessation counselling - a role for the dental profession? Br Dent J 1995; 179: 411-415.

21. Johnson N W, Lowe J C, Warnakulasuriya S. Tobacco cessation activities of UK dentists in primary care: Signs of improvement. Br Dent J 2006; 200: 85-89.

22. Block D E, Block L E, Hutton S J, Johnson K M. Tobacco counselling practices of dentists compared to other health care providers in a midwestern region. J Dent Educ 1999; 63: 821-827.

23. Campbell H S, Macdonald J M. Tobacco counselling among Alberta dentists. J Can Dent Assoc 1994; 60: $218-226$.

24. Dolan T A, McGorray S P, Grinstead-Skigen C L Mecklenburg R. Tobacco control activities in US dental practices. JAm Dent Assoc 1997; 128: 1669-1679.

25. Fried J L, Cohen L A. Maryland dentists' attitudes regarding tobacco issues. Clin Prev Dent 1992; 14: 10-16.

26. Beaglehole R H, Watt R G. Helping smokers stop. A guide for the dental team. Health Development Agency, 2004.

27. Victoroff $K Z$, Lewis $R$, Ellis E, Ntragatakis M. Patient receptivity to tobacco cessation counseling in an academic dental clinic: a patient survey. J Public Health Dent. 2006; 66: 209-211.

28. Raw M, McNeill A, Watt J. The case for commissioning smoking cessation services. World Health Organization Europe Partnership Project and SmokeFree London, 2001. http://www.ash.org.uk/ cessationcase $>$ [accessed 4 February 2008].

29. McEwen A, West R, Owen L, Raw M. General practitioners' view on and referral to NHS smoking cessation services. Public Health 2005; 119: 262-268.

30. Helgason A, Lund K. General practitioner' perceived barriers to smoking cessation - results from four Nordic countries. Scand J Public Health 2002; 30: 141-147.

31. Cannick G F, Alice B S, Horowitz M, Reed S G et al. Opinions of South Carolina dental students toward tobacco use interventions. J Public Health Dent 2006; 66: 44-48.

32. Robinson M. Tobacco and oral health; a survey of dental education and training in tobacco issues. Health Development Agency, 2005.

33. Chestnutt I G. Smoking and oral health. Cardiff University School of Dentistry, 2008.

34. Weaver R G, Whittaker L, Valachovic R W, Broom A. Tobacco control and prevention effort in dental education J Dent Educ 2002; 66: 426-429.

35. Johnson N W. The role of the dental team in tobacco cessation. Eur J Dent Educ 2004; 8: 18-24.

36. Plasschaert A J M, Holbrook W P, Delap E, Martinez C, Walmsley A D. Profile and Competences for the European Dentist Published in November by the Association for Dental Education in Europe and the DentEd III Thematic Network Project. 2004.

37. Quality Assurance Agency for Higher Education. Subject Benchmark Statements. Academic Standards - Dentistry Gloucester: Quality Assurance Agency for Higher Education 2002.

38. General Dental Council. The first five years $-a$ framework for undergraduate dental education, 2nd ed. London: General Dental Council, 2002.

39. Binnie V. Smoking cessation. Br Dent J 2004; 196: 188. 